Implementasi Kurikulum Cambridge ... (Nurul Waridatil Zulfa)

\title{
IMPLEMENTASI KURIKULUM CAMBRIDGE DI SEKOLAH DASAR INTERNASIONAL AL AL-ABIDIN SURAKARTA DAN SEKOLAH DASAR INTEGRAL WALISONGO SRAGEN
}

\author{
Nuhla Fauziyyatun Nafisah \\ Guru SDII (Sekolah Dasar Islam Internasional) Al-Abidin Surakarta \\ E-Mail:
}

\begin{abstract}
This study aims to describe the implementation of the Cambridge curriculum in the International Islamic Elementary School Al-Abidin Surakarta and Integral Walisongo Elementary School Sragen as well as to find the points of excellence and weakness of the existing Cambridge curriculum implementation at the school. This research type is qualitative research, the subject of this research consist of principal, vice principal of curriculum section, Human Resources Development, International Class Program teachers, and students in International Islamic Elementary School Al-Abidin Surakarta and SD Integral Walisongo Sragen. Technique of collecting data through observation, interviews, and documentation. Technique of analyzing data used descriptive qualitative. The results of this study indicate that the implementation of the Cambridge curriculum in the International Islamic Elementary School Al-Abidin Surakarta runs well, this can be known through several findings, first of the Cambridge curriculum implementation process is routinely implemented at the beginning of the new school year by involving all levels teachers who teach in this program with special workshop held for teachers before the teaching and learning activities begin. Second, in the implementation of this curriculum, teachers are able to build enthusiastic learners and able to create a fun learning, so learners are more active and willing to try to understand the lesson of this curriculum. Third in the evaluation process goes well and learners are categorized able to meet the standards provided by Cambridge. Seeing the proud results we can see the advantages of the implementation of this Cambridge curriculum one of them is the complexity of the mindset of students increased, there are still some weaknesses, such as on the implementation of student learning is still difficult to understand the story in Cambridge math lesson, learners translate the story, also looking for ways to solve the problem. In addition the weakness found in the field is less effective in English language communication in the school. It occurs because of the lack of maximum vocabulary given to learners.
\end{abstract}

Keywords: Curriculum Implementation; the Cambridge curriculum.

\begin{abstract}
Abstrak: Penelitian ini bertujuan untuk mendiskripsikan implementasi kurikulum Cambridge di SD Islam Internasional Al-Abidin Surakarta dan SD Integral Walisongo Sragen sekaligus untuk menemukan titik-titik keunggulan dan kelemahan implementasi kurikulum Cambridge yang ada pada sekolah tersebut. Jenis penelitian ini adalah penelitian kualitatif, subjek penelitian ini terdiri dari kepala sekolah, wakil kepala sekolah bagian kurikulum, Human Resources Development, guru-guru Internasional Class Program, dan peserta didik di SD Islam Internasional Al-Abidin Surakarta dan SD Integral Walisongo Sragen. tehnik pengumpulan data melalui observasi, wawancara, dan dokumentasi. tehnik analisis data secara deskripstif kualitatif. Hasil penelitian ini menunjukkan bahwa dalam implementasi kurikulum Cambridge di SD Islam Internasional Al-Abidin Surakarta dan SD Integral Walisongo Sragen berjalan dengan baik, hal ini bisa diketahui melalui beberapa temuan, yaitu pertama dari proses perencanaan implementasi kurikulum Cambridge ini rutin dilaksanakan pada awal tahun ajaran baru yaitu dengan melibatkan seluruh jajaran guru yang mengajar di
\end{abstract}


program ini dengan diadakan workshop khusus untuk guru sebelum kegiatan belajar mengajar dimulai. kedua, dalam pelaksanaan kurikulum ini, guru mampu membangun antusias peserta didik dan mampu menciptakan pembelajaran yang menyenangkan, dengan begitu peserta didik semakin aktif dan mau berusaha dalam memahami pelajaran kurikulum ini. ketiga dalam proses evaluasi berjalan dengan baik dan peserta didik dikategorikan mampu memenuhi standar yang diberikan oleh Cambridge. Melihat hasil yang membanggakan kita dapat melihat keunggulan dari implementasi kurikulum Cambridge ini salah satunya adalah kompleksitas pola pikir peserta didik meningkat meskipun demikian, masih terdapat beberapa kelemahan, diantaranya pada pelaksanaan pembelajaran siswa masih kesulitan dalam memahami soal cerita yang terdapat dalam pelajaran math Cambridge, karena disamping peserta didik menerjemahkan ceritanya, juga mencari cara untuk menyelesaikan soal tersebut. selain itu juga kelemahan yang saya temui di lapangan adalah kurang efektif dalam komunikasi Bahasa inggris di sekolah tersebut. hal itu terjadi karena kurang maksimalnya kosa kata yang diberikan kepada peserta didik.

Kata Kunci: Implementasi Kurikulum ; Kurikulum Cambridge.

\section{PENDAHULUAN}

Pendidikan memiliki peran yang sangat signifikan dalam kehidupan bermasyarakat, terutama dalam memenuhi kebutuhan hidup yang kompleks dan berkembang seiring dengan perkembangan zaman. Oleh karena itu, ada perangkat penting yang harus dimiliki oleh suatu lembaga pendidikan, guna menciptakan pendidikan yang relevan dengan kemajuan masyarakat. Perangkat tersebut termuat dan tergambar dalam bentuk kurikulum.

Kurikulum merupakan seperangkat "alat" mata pelajaran yang dipakai guru dalam proses pembelajaran. Ia juga menjadi elemen penting untuk mencapai tujuan pendidikan itu sendiri. Jadi tanpa adanya kurikulum, mustahil suatu pendidikan akan berjalan dengan sempurna. ${ }^{1}$

Kurikulum mengarahkan segala bentuk aktivitas pendidikan demi mencapai tujuan pendidikan. Menurut Mauritz Johnson, kurikulum merupakan suatu

1 Muthoifin. Pemikiran Pendidikan Ki Hadjar Dewantara Dalam Perspektif Pendidikan Islam, dalam https://scholar. google.co.id/citations?user=6rI6mtoAAAA$\mathrm{J} \& \mathrm{hl}=\mathrm{en} \# \mathrm{~d}=\mathrm{gs}$ _md_cita-d \&u=\%2Fcitations\%3Fview_op\%3 Dview_citation\%26hl\%3Den\%26user\%3D6rI6mtoAAAAJ\%26cstart\%3D20\%26pagesize\%3D80\%26citation_for_view\%3D6rI6mtoAAAAJ\%3ABJtnxTr0fRcC $\% 26$ tzom\%3D-420 rencana pendidikan, memberikan pedoman dan pegangan tentang jenis, lingkup, dan urutan isi, serta proses pendidikan. ${ }^{2}$

Ada delapan Standar Nasional Pendidikan (SNP) yang dijadikan acuan dan tolak ukur untuk menilai apakah suatu satuan pendidikan itu berkualitas tinggi atau rendah. Seperti yang dituangkan dalam peraturan pemerintah (PP) Republik Indonesia Nomor 19 tahun 2005 tentang Standar Nasioal Pendidikan, ${ }^{3}$ bahwa Standar Nasional Pendidikan bertujuan menjamin mutu pendidikan nasional dalam rangka mencerdaskan kehidupan bangsa dan membentuk watak serta peradaban bangsa yang bermanfaat.

Standar Nasional Pendidikan meliputi standar isi, standar proses, standar kompetensi lulusan, standar pendidik dan tenaga kependidikan, standar sarana dan prasarana, standar pengelolaan, standar pembiayaan, dan standar penilaian pendidikan. Salah satunya standar isi adalah ruang lingkup materi dan tingkatan kompetensi untuk mencapai kompetensi lulusan pada jenjang dan jenis pendidikan tertentu.

2 Nana Syaodih Sukmadinata,Pengembangan Kurikulum (teori dan praktik)(Bandung : Remaja Rosdakarya,2001), hlm.5.

3 Mulyasa, Kurikulum yang Disempurnakan, (Bandung : Rosda Karya, 2007), hlm. 24. 
Standar isi memuat kerangka dasar dan stuktur kurikulum, beban belajar, kalender pendidikan. Standar isi dan standar proses memiliki saling keterkaitan, standar proses merupakan pelaksanaan dari standar isi yang mencakup dalam setiap tahun pendidik melakukan perencanaan, pelaksanaan, perencanaan serta pengawasan demi tercapainya pembelajaran yang efektif, proses pembelajaran termasuk silabus dan rencana pelaksanaan pembelajaran, kegiatan pelaksanaan kurikulum dilaksanakan dengan inspiratif dan interaktif, penilaian dapat menggunakan tes tulis atau praktik, dan pengawasan melalui pemantauan, supervisi, evaluasi, pelaporan dan pengambilan solusi.

Kurikulum Cambridgememberikan pengaruh besar terhadap keberhasilan peserta didik dalam pelaksanaan kurikulum tersebut, terdapat materi dan kerangka kurikulum yang jelas dan pengimplementasiannya masuk kepada standar proses dengan menjalankan yang sudah direncanakan secara matang yaitu dengan melaksanakan pembelajaran Cambridge dengan sangat menyenangkan, adanya framework (silabus), lesson plan atau Rencana Pelaksanaan Pembelajaran (RPP), dan adanya evaluasi demi tercapainya hasil yang lebih baik lagi.

Pada penelitian ini menggunakan teori tentang tinjauan kurikulum, menurut beberapa pandangan tokoh, buku yang digunakan dalam acuan dalam teori yang pertama ini adalah buku "Dasar-dasar Pengembangan Kurikulum" Rosdakarya 2013, buku ini membahas secara rinci terkait kurikulum secara umum serta tahapan dalam implementasi kurikulum. Kemudian teori tentang kurikulum Cambridge sebagai upaya pengembangan mutu sekolah. Pembahasan tentang kurikulum Cambridge peneliti mengambil data langsung dari link resmi milik Cambridge International Examination yaitu http://www.Cambridge. international.org. Sedangkan pembahasan tentang upaya pengembangan mutu sekolah peneliti mengambil teori yang bisa dijadikan dasar menganalisis yaitu dari bukunya Mohamad Ali yang berjudul "Reinvensi Pendidikan Muhammadiyah", Al-wasat Publishing House 2010. Buku ini membahas tentang tahapan dalam mengembangkan mutu sekolah, yaitu berawal dari tahap inisiasi, implementation, continuation, outcome.

Kurikulum Internasional yang populer digunakan di Indonesia yaitu kurikulum CambridgeInternasional Examinations(CIE). CambridgeInternasional Examinations(CIE) adalah bagian dari Cambridge Assesment Group, organisasi dibawah University of Cambridge. Jaringan penyelenggara sistem kurikulum ini telah digunakan lebih dari 150 negara. Kurikulum ini menekankan fleksibilitas, sejak pendidikan dasar hingga menengah. ${ }^{4}$

Cambridge IGCSE, Cambridge AS dan A level telah diakui oleh berbagai universitas dan perusahaan dunia terkemuka sebagai bukti terdepan di dalam kemampuan akademis. Cambridge IGCSE, adalah kurikulum Internasional yang paling popular di dunia selama 16 tahun, dan sekolah yang menerapkan kurikulum Cambridge ini sejumlah 3700 sekolah di 140 Negara. Sedangkan, Cambridge AS dan A level, yang diperuntukkan bagi peserta didik berusia 16 hingga 19 tahun, telah diimplementasikan di lebih dari 125 negara. ${ }^{5}$

Kurikulum ini merupakan upaya sekolah dalam mengembangkan mutu pendidikan, terdapat beberapa sekolah di Indonesia yang menggunakan kurikulum kombinasi dengan mengacu pada kurikulum Cambridge, ini dilakukan karena sekolah berkeinginan menghasilkan lulusan berkualitas yang diakui secara Internasional.

Lulusan peserta didik dari lembaga kurikulum Cambridgedapat melanjutkan ke lembaga yang menggunakan kurikulum yang sama tanpa mengikuti ujian kesetaraan. Sebagaimana yang berlaku di SD IslamInternasional Al-Abidin Surakarta dan

4 Lee Satryo Adjie, Komparasi IB dan CIE dalam Pendidikan Dasar. (Online), (http://cieofuai. wordpress.com, diakses 29 oktober 2017).

5 Ibid. 
SD Integral Walisongo Sragen yang sudah mengadopsi kurikulum Cambridgesebagai peningkatan mutu sekolah.

Kurikulum yang sudah dirancang dengan baik tidak akan ada artinya tanpa proses pembelajaran. Kurikulum dan pembelajaran merupakan dua istilah yang berbeda tetapi tidak dapat dipisahkan satu dengan lainnya. Keduanya mempunyai posisi yang sama. Kurikulum merupakan segala sesuatu yang ideal, sedangkan pembelajaran merupakan realisasi dari idealisme atau gagasan. Jika kurikulum adalah programnya, maka pembelajaran merupakan implementasi. Jika kurikulum merupakan teorinya, maka pembelajaran adalah penerapannya. Jika kurikulum merupakan teorinya, maka pembelajaran merupakan praktiknya. Apa yang dilihat dan dilakukan dalam pembelajaran, itulah sesungguhnya kurikulum yang nyata. ${ }^{6}$

Setiap lembaga pendidikan memiliki cara tersendiri dalam melaksanakan kegiatan pendidikannya. Begitu juga yang terjadi di SDII Al-Abidin Surakarta dan SD Integral Walisongo Sragen. Kedua sekolah tersebut berada dalam naungan Islam, akan tetapi SDII Al-Abidin Surakarta dan SD Integral Walisongo Sragen bisa menerapkan kurikulum Nasional dan kurikulum Internasional (kurikulum Cambridge).

Tujuannya untuk mencetak peserta didik yang tidak hanya unggul dalam Iptek saja namun juga memiliki keunggulan mempunyai karakter Islami, selain itu juga menggunakan kurikulum Cambridgeguna mencetak generasi baru yang unggul dalam beriman dan bertaqwa kepada Allah SWT. Berakhlak karimah dan Iptek dalam skala Nasional maupun Internasional.

Paparan di atas penulis tertarik untuk melakukan penelitian tentang kurikulum Cambridgeyang diterapkan di sekolah tersebut, karena sekolah tersebut notabennya berada di bawah naungan sekolah Islam, namun bisa mengadopsi kurikulum Cambridgeyang cakupannya

6 Zainal Arifin, Konsep dan Model Pengembangan Kurikulum (Bandung: PT Remaja Rosdakarya, 2011), hlm.23-24. mendunia. Begitu juga dengan SD Integral Walisongo yang kategorinya sekolah Islam bahkan di dalamnya menyediakan pesantren untuk peserta didik, mata pelajaran keagamaannya jauh lebih banyak dari pada pelajaran umum, namun bisa mengadopsi kurikulum Cambridgeyang kategorinya mendunia, dengan begitu SD Integral Walisongo Sragen menciptakan inovasi untuk mempersiapkan generasi yang lebih maju dan mendunia yaitu dengan menerapkan kurikulum Cambridgesebagai pengembangan mutu sekolahnya.

Berdasarkan latar belakang di atas, peneliti tertarik untuk melakukan penelitian dan pengkajian lebih dalam terkait pelaksanaan kurikulum Internasional Cambridge. Oleh karena itu, penulis mengusung judul penelitian "Implementasi Kurikulum Cambridgedi SD Islam Internasional Al-Abidin Surakarta dan SD Integral Walisongo Sragen Tahun 2017/2018".

\section{METODE PENELITIAN}

Penelitian ini termasuk penelitian lapangan (field research), sebab data yang dikumpulkan terhadap objek yang bersangkutan secara langsung. Penelitian ini merupakan penelitian yang bersifat deskriptif kualitatif, yakni dengan prosedur penelitian yang menghasilkan data deskriptif berupa kata-kata tertulis atau lisan dari orang-orang yang diperlukan agar dapat diamati yang dilakukan dalam kehidupan yang nyata dan sebenarnya. ${ }^{7}$

Peneliti melakukan penelitian terhadap Implementasi Kurikulum Cambridgedi SD Islam Internasional Al-Abidin Surakarta dan SD Integral Walisongo Sragen Tahun 2017/2018. Metode pengumpulan data terdiri dari metode observasi adalah Kepala sekolah, wakil kepala sekolah bagian kurikulum, Human Resources Development, guru dan peserta didik.

Peneliti menggunakan metode

7 Lexi J. Moleong, Metodologi Penelitian Kualitatif (Bandung: Remaja Rosdakarya Offset,2007), hlm.4 
wawancara dari sumber yang relevan berupa pendapat, kesan, pengalaman, pemikiran untuk mendapatkan informasi secara mendalam. Wawancara tersebut dilakukan kepada kepala sekolah SD Islam Internasional Al-Abidin Surakarta dan SD Integral Walisongo Sragen, wakil kepala sekolah bagian kurikulum, Human Resources Development, Guru dan Peserta didik. peserta didik yang diwawancarai berjumlah 2 orang dari masing-masing sekolah. Metode Dokumentasiakan diperoleh data tentang gambaran umum dan sejarah berdirinya sekolah dari SD Islam Internasional Al-Abidin Surakarta dan SD Integral Walisongo Sragen.

Keabsahan data menggunakan teknik trianggulasi dengan sumber. teknis analisis data dengan cara reduksi data, penyajian data, dan penarikan kesimpulan.

\section{HASIL PENELITIAN}

Implementasi Kurikulum Cambridge di SDII Al-Abidin Surakarta dan SD Integral Walisongo Sragen. Secara umum implementasi kurikulum itu dibagi 3, yaitu:

\section{Perencanaan kurikulum}

Pada sebuah proses pembelajaran, ada hal- hal yang harus dipersiapkan terkait keadministrasian, dalam kurikulum Cambridge ini memiliki sistem administrasi yang begitu mudah dan tidak mempersulit guru, dengan begitu guru tidak dibebankan dalam menyiapkan keadministrasian terlalu banyak, karena Cambridge University memiliki sistem yang simple, agar guru lebih konsen dalam proses pengajaran pada peserta didik dibanding dengan halhal yang berkaitan dengan administrasi pendidikan.

Sebelum melaksanakan pembelajaran di kelas, ada beberapa hal yang harus dipersiapkan oleh seorang guru. Hal yang mendasar yang harus dipersiapkan oleh guru dalam proses pembelajaran adalah menyiapkan administrasi pembelajaran, yaitu: Program Tahunan (Prota), Program Semester (Promes), framework (silabus),
Rencana Pelaksanaan Pembelajaran (RPP), dan evaluasi pembelajaran.

Berdasarkan hasil pengamatan peneliti, berkenaan dengan perencanaan yang dilakukan oleh guru diperoleh gambaran bahwa guru di SDII Al-Abidin Surakarta dan SD Integral Walisongo Sragen sudah mempersiapkan lesson plan (RPP) secara keseluruhan di awal semester, sehingga hasil pembuatan Lesson plan akan divalidasi oleh bagian kurikulum sebelum digunakan untuk pedoman mengajar di kelas.

Dalam proses pembuatan lesson plan semuanya bisa berpedoman pada framework, framework merupakan silabus dari Cambridgekhusus untuk guru pengajar, komponen yang harus ada pada pembuatan RPP sudah ada semua di dalam framework, seperti tujuan pembelajaran, Standar Kompetensi, Komptensi Dasar, alokasi waktu, materi pembelajaran, metode pembelajaran, dan media yang digunakan dalam belajar. Semua sudah tertuang dalam framework.

Selain membuat lesson plan, di SDII Al-Abidin Surakarta kerap kali membuatworksheet, sebagai latihan dan guru mencoba melihat kefahaman peserta didik melalui worksheet yang diberikan. Sama halnya dengan Guru ICP SD Integral Walisongo Sragen dalam pembuatan worksheet, karena dengan begitu peserta didik semakin terlatih dengan soal-soal yang diberikan oleh guru, sehingga ketika ujian peserta didik hasilnya maksimal.

Melihat dari penjelasan di atas, peneliti menganalisa bahwa lancarnya suatu pengajaran tergantung pada admministrasi yang sesuai dengan kebutuhan dan perencanaan yang baik, dengan begitu menurut peneliti proses perencanaan yang dilakukan oleh SDII Al-Abidin Surakarta dan SD Integral Walisongo Sragen dalam merencanakan proses pembelajaran cukup terencana dan secara terstruktur sangat bagus dan efisien.

Namun, sesuai dengan pengamat peneliti bahwa di kedua sekolah tersebut tidak mempunyai program tahunan dan program semester khusus untuk kurikulum 
Cambridge, karena bukan suatu kewajiban yang diharuskan dari pusat Cambridge itu sebagai adminstrasi yang harus ada. Hanya saja pada kedua sekolah tersebut membuat semacam program kerja yang akan dilaksanakan selama satu semester kedepan, perumusan program kerja tersebut dilaksanakan awal semester ketika workshop guru-guru.

\section{Pelaksanaan kurikulum}

Proses pelaksanaan kurikulum terdapat proses pelaksanaan pembelajaran, dalam pelaksanaan kegiatan pembelajaran di kelas, terbagi menjadi tiga tahap, yakni:

1. Tahap pendahuluan

Pendahuluan adalah kegiatan awal yang dilakukan guru saat memulai kegiatan pembelajaran. Kegiatan ini dimaksudkan untuk melihat kesiapan siswa dalam belajar. Guru akan menanyakan terkait kehadiran siswa, review materi sebelumnya, memberi kesempatan kepada peserta didik untuk bertanya materi yang belum difahami sebelumnya.

2. Kegiatan pokok

Kegiatan pokok adalah kegiatan penyampaian materi pembelajaran. Kegiatan inti pembelajaran yang dilakukan guru dengan melibatkan keikutsertaan peserta didik di dalamnya sehingga menghasilkan capaian tujuan pembelajaran yang telah direncanakan.

Kegiatan pokok ini mengarahkan peserta didik pada penguasaan materi pelajaran melalui berbagai kegiatan yang dilakukan dengan menggunakan pendekatan dan metode yang tepat. Sehingga menghasilkan pembelajaran yang bermakna bagi peserta didik.

Kegiatan pokok yang dilaksanakan di SDII Al-Abidin memiliki strategi dalam pelaksanaan pembelajaran. Dimulai dari peserta didik mendengarkan penjelasan dari guru terkait materi yang sedang diajarkan dengan menggunakan bahasa pengantar
Bahasa Inggris, kemudian apabila dirasa sudah faham maka guru akan melanjutkannya. Apabila peserta didik tidak memahami maka guru akan mengulang dengan menjelaskan menggunakan sinonim dari kalimat yang tidak difahami, akan tetapi jika dengan strategi itu peserta didik juga tidak faham maka guru boleh menjelasakan menggunakan bahasa Indonesia. Menurut peneliti peserta didik mengalami kesulitan ketika menerima pelajaran science Cambridge dan math cambridge. Pada bagian science Cambridge peserta didik merasa kesusahan ketika memahami kalimat. Ketika pada math Cambridge yang dikeluhkan anak-anak adalah ketika mendapatkan soal dengan bahasa inggris.

Berbeda dengan SD Integral Walisngo Sragen, apabila mendapati siswa yang tidak memahami apa yang sedang diajarkan maka guru akan menerjemahkan langsung menggunakan bahasa Indonesia agar siswa memahaminya. Terkait semua mata pelajaran diterjemahkan dalam Bahasa Inggris, usaha tersebut melatih siswa untuk terbiasa dengan menggunakan Bahasa inggris, kecuali pelajaran dinniyah. Dan tidak ketinggalan pula, ketika materi yang disampaikan ada kaitannya dengan keislaman, maka akan dikaitkan dengan realitas nilai keislaman, menurut peneliti itu merupakan prestasi yang cukup bagus karena, siswa benar-benar disiapkan dalam menghadapi tantangan mendatang yang bukan hanya menang dalam hal duniawi saja tapi juga menguasi ilmu agama.

Selain itu dalam proses pembelajaran tentunya ada metode, sumber, media yang digunakan. Menurut pengamatan peneliti di SDII AlAbidin Surakarta dalam penggunaan 
metode pembelajaran cukup variatif, terkadang dalam satu kali tatap muka menggunakan beberapa metode pembelajaran. Metode yang digunakan cukup menyenangkan sehingga anak-anak tidak jenuh dalam menerima materi. anak-anak selalu dilibatkan ketika proses pembelajaran berlangsung, metode yang digunakan seperti discuss, grup, game dan lain sebagainya.

Berbeda dengan SD Integral Walisongo Sragen, cenderung menggunakan metode ceramah dan active learning yang lainnya. Namun cukup efektif karena guru selalu memancing siswa agar ikut terlibat dalam proses pembelajaran, dengan begitu siswa semakin aktif dan berani bertanya apabila siswa mengalami kesulitan.

Terkait sumber belajar yang digunakan SDII Al-Abidin Surakarta dan SD integral walisongo Sragen tidak stagnan dalam penggunaan satu sumber seperti buku Cambridge saja, melainkan menggunakan internet dan buku-buku lainnya yang berkaitan dengan materi yang diajarkan. Menurut pengamat peneliti, penggunaan internet sebagai sumber cukup efektif, karena di internet akan menemukan banyak sekali refrensi yang bisa dijadikan sumber dalam proses pembelajaran.

Dengan demikian dapat ditarik kesimpulan bahwa dalamimplementasi pembelajaran guru telah melaksanakan kegiatan belajar dengan baik, guru menunjukkan penguasaan yang baik terhadap materi yang disampaikan kepada siswa, mengaitkan materi pelajaran dengan realitas kehidupan, mengaitkan pelajaran science dengan nilai-nilai islam. Dengan begitu terlaksananya kurikulum Cambridge akan menambah ketaatan kepada Allah karena peserta didik selalu diajak dalam mengingat dan mensyukuri nikmat Allah SWT.
3. Kegiatan akhir / penutupan.

Kegiatan akhir dari pembelajaran adalah kegiatan penutup. Kegiatan yang dilakukan guru untuk mengakhiri seluruh rangkaian kegiatan pembelajaran.

Sesuai dengan pengamatan peneliti, kegiatan yang dilakukan pada tahap ini adalah guru membuat garis besar persoalan yang telah diajarkan, memastikan peserta didik semuanya sudah faham dan memberi evaluasi sebelum ditutup pertemuan kali ini.

SDII Al-Abidin Surakarta menggunakan game sebagai penutup dari sebuah akhir pertemuan, dengan begitu anak-anak berantusias kembali dalam menanggapi gurunya. Game nya berupa pertanyaan yang berkaitan dengan materi yang telah disampaikan. Begitu juga dengan SD Integral Walisongo menggunakan tebak soal sehingga siswa berebut untuk menjawabnya, dari kegiatan itu anak-anak semakin faham yang telah dipelajarinya. Cara ini cukup efektif dan efisien karena tidak membuat anak bosan dan semakin semangat dalam belajar kurikulum cambridge.

\section{Evaluasi kurikulum}

Penilaian atau evaluasi kurikulum mempunyai posisi yang penting dalam kegiatan belajar mengajar, karena adanya evaluasi hasil belajar, keberhasilan pengajaran akan dapat diketahui. Dilihat dari evaluasi implementasi kurikulum Cambridge, dalam hal pembelajarannya peserta didik cenderung mampu mengikuti apa yang diajarkan oleh gurunya. Peserta didik ICP SDII Al-Abidin Surakarta 80\% mampu mengikuti pelajaran kurikulum Cambridge dan memenuhi standar. Sama halnya dengan SD Integral Walisongo Sragen, peserta didik dikatakan mampu memenuhi standar Cambridge, meningkat sebanyak $80 \%$ setelah diadakan pembelajaran di Pare.

Prosentasi yang didapat cukup unggul, 
itu diraih dengan mengikuti tes yang diadakan setiap semester yang disebut Center Progression Test (CPT), dan setiap tahun yang disebut dengan International Progression Test (IPT). Evaluasi pembelajaran itu soal ujiannya langsung dari pusat yaitu Cambridge University.

Selain adanya ujian CPT dan IPT, ada evaluasi yang disebut dengan Check point, itu merupakan evaluasi akhir tahun disetiap jenjang. Seperti halnya Ujian Nasional yang dilakukan di akhir tahun jenjang.

Menurut sajian di atas, kita bisa melihat bahwa dalam proses evaluasi pembelajaran yang diberikan di masing-masing sekolah memiliki banyak kesamaan, hanya saja yang membedakan adalah teknis pelaksanaannya. Bisa ditarik kesimpulan bahwa evaluasi kurikulum Cambridge berjalan cukup lancar dan memudahkan peserta didik untuk melanjutkan ke tahap selanjutnya. Peserta didik mampu mengerjakan soal sesuai dengan kemampuannya, dan mendapatkan nilai yang signifikan tinggi.

Keunggulan dan kelemahan Implementasi kurikulum Internasional Cambridge di SDII Al-Abidin Surakarta dan SD Integral Walisongo Sragen.

Banyak keunggulan yang diraih setelah SDII Al-Abidin Surakarta menerapkan kurikulum Cambridge, mutu kurikulum Cambridge merupakan kurikulum yang melebihi kurikulum nasional, sehingga ketika peserta didik mempelajari menggunakan kurikulum ini maka kompleksitas berfikirnya jauh lebih tinggi dibanding dengan peserta didik yang hanya belajar menggunakan kurikulum 2013 saja, dan peserta didik lebih berani dan tertantang menghadapi materi materi yang berstandar internasional lainnya.

Serupa dengan yang dipaparkan kepala sekolah SD Integral Walisongo Sragen, bahwa dengan diterapkannya kurikulum Cambridge di sekolah ini bisa mendongkrak popularitas masyarakat untuk memilih program sekolah yang berstandar internasional, dan peserta didik terlihat jauh lebih siap menghadapi tantangan masa depan.

Dari pemaparan di atas, penulis menarik kesimpulan bahwa keunggulan dari kurikulum Cambridge sangat mempengaruhi hasil belajar siswa, dan memiliki keuntungan yang jauh lebih besar. Peserta didik menjadi pola pikirnya semakin terarah dan siap berfikir dengan kompleksitas yang tinggi, serta peserta didik lebih siap untuk dicetak sebagai generasi dakwah Islamiyah di tingkat dunia.

Terkait dengan kelemahan penerapan kurikulum Cambridge yang terjadi di SDII Al-Abidin Surakarta dan SD Integral Walisongo Sragen adalah keduanya memiliki keluhan yang sama, yaitu kurang mampu dalam memahami kalimat dalam bahasa inggris, memahami soal cerita yang ada pada pelajaran math Cambridge, kurang faham terkait susunan kalimat yang ada pada science Cambridge. Itu tidak lain juga disebabkan karena kurangnya diterapkan komunikasi dalam bahasa inggris ketika dirumah bersama orang tuanya. Dengan begitu, pembiasaan terhadap anaknya kurang efektif.

Setelah melihat keunggulan dan kelemahan diatas, peneliti mengamati bahwa, poin positif yang dapat diambil dan dijadikan pelajaran itu sangat banyak, sehingga harapan akan mensukseskan hasil yang terbaik untuk peserta didik akan menjadi power tersendiri. Di sisi lain itu adalah hasil yang saat ini, jadi masih ada kesempatan untuk semakin lebih baik agar persiapan untuk menghadapi tantangan masa depan itu semakin siap dan semangat.

Secara keseluruhan dalam penerapan kurikulum Cambridge dari segi penguasaan materi dan pengefektifan komunikasi Bahasa Inggris di Al-Abidin lebih berjalan dengan baik dan lancar. Namun, dalam segi administratif SD Integral lebih terstruktur dan lebih rapi.

\section{PENUTUP}

Hasil penelitian ini menunjukkan bahwa dalam implementasi kurikulum 
Cambridge di SD Islam Internasional Al-Abidin Surakarta dan SD Integral Walisongo Sragen berjalan dengan baik, hal ini bisa diketahui melalui beberapa temuan, yaitu pertama dari proses perencanaan implementasi kurikulum Cambridge ini rutin dilaksanakan pada awal tahun ajaran baru yaitu dengan melibatkan seluruh jajaran guru yang mengajar di program ini dengan diadakan workshop khusus untuk guru sebelum kegiatan belajar mengajar dimulai. kedua, dalam pelaksanaan kurikulum ini, guru mampu membangun antusias peserta didik dan mampu menciptakan pembelajaran yang menyenangkan, dengan begitu peserta didik semakin aktif dan mau berusaha dalam memahami pelajaran kurikulum ini. ketiga dalam proses evaluasi berjalan dengan baik dan peserta didik dikategorikan mampu memenuhi standar yang diberikan oleh Cambridge.
Keunggulan dan kelamahan implementasi kurikulum Cambridge Melihat hasil yang membanggakan kita dapat melihat keunggulan dari implementasi kurikulum Cambridge ini salah satunya adalah kompleksitas pola pikir peserta didik meningkat meskipun demikian, masih terdapat beberapa kelemahan, di antaranya pada pelaksanaan pembelajaran siswa masih kesulitan dalam memahami soal cerita yang terdapat dalam pelajaran math Cambridge, karena disamping peserta didik menerjemahkan ceritanya, juga mencari cara untuk menyelesaikan soal tersebut. Selain itu juga kelemahan yang saya temui di lapangan adalah kurang efektif dalam komunikasi bahasa inggris di sekolah tersebut. Hal itu terjadi karena kurang maksimalnya kosa kata yang diberikan kepada peserta didik

\section{DAFTAR PUSTAKA}

Adjie, Lee Satryo. 2012.Komparasi IB dan CIE dalam Pendidikan Dasar. (Online), (http:// cieofuai.wordpress.com, diakses 29 oktober 2017)

Arifin, Zainal. 2011. Konsep dan Model Pengembangan Kurikulum. Bandung: PT Remaja Rosdakarya.

Moleong, Lexi J. 2011.Metodologi Penelitian Kualitatif, Bandung: Remaja Rosdakarya Offset.

Mulyasa, 2008. Implementasi Kurikulum Tingkat Satuan Pendidikan, Jakarta: Raja Grafindo Persada.

Muthoifin. Pemikiran Pendidikan Ki Hadjar Dewantara Dalam Perspektif Pendidikan Islam, dalam https://scholar.google.co.id/citations?user=6rI6mtoAAAAJ\&hl=en\#d=gs_ md_cita-d\&u=\%2Fcitations\%3Fview_op\%3Dview_citation $\% 26 \mathrm{hl} \% 3$ Den $\% 26$ user\%3D6rI6mtoAAAAJ\%26cstart\%3D20\%26pagesize\%3D80\%26citation_for_ view\%3D6rI6mtoAAAAJ\%3ABJtnxTr0fRcC\%26tzom\%3D-420Konsep Guru dan Murid dalam Pandangan Ibn Jama'ah, dalam

Sukmadinata, Nana Syaodih. 2009. Pengembangan Kurikukum Teori dan Praktek Bandung: PT.Remaja Rosdakarya. 